\title{
Practice of Modern Sport Teaching Method Under the Horizon of Innovative Education
}

\author{
Xuehua Li \\ Department of Physical Education, Xi'an International University, Xi'an, 710077, China
}

Keywords: Horizon of innovative education; modern sport teaching; specific method

\begin{abstract}
The innovative education path follows the principle of origin under the creative architecture, adopts the scientific teaching mode, cultivates the cognitive personality and creates the new teaching of sports. The sports teaching in the modern times should embody the principle of origin - innovation and change the origin exam-oriented purpose to the innovation purpose in the new times. Only in this way, it can promote the sports to conduct unique subject reform and accept innovative education and also improve the effects within the category of sports teaching. The modern sports subject provides a unique open environment and unique physical exercise-based site to students. Students can discriminate the thinking path of sports through daily observation and improve their physical quality by preset exercise process. The original purpose of sports teaching is to cultivate the innovative new cognition and increase the sports thinking under the creative architecture and integrate the unique underlying mechanism of innovative education into the usual teaching. This changes the original cognitive channel, encourages students' participation and solves the teaching problem in modern times.
\end{abstract}

\section{Discriminate the basic connotation}

(I) New education connotation

The innovative new education is to cultivate the underlying thinking potential by following the thinking path within the category of law. Based on this, the underlying multiple potentials of subjects that accept education are motivated and these subjects are provided with clear innovative guidance and guided to build their own innovative architecture and promote the original independent spirit. It is clear that the innovative education is not incorporated into the cognitive model in a single architecture, but has thinking characteristics. The innovative education is set as the unique product of the development of times, which puts forward teaching requirements under the new situation in the era that the knowledge economy extends.

(II) Discriminate the teaching thought

Under the fundamental thought of innovative education, the sports teacher should accept the cognitive status quo in the real situation and believes the underlying potential of students. In addition, the sports teacher should also properly guide students through the preset correct path and solve the associated problems in the cognition. Due to the time that students contact this subject, the teacher should discriminate this underlying difference, guide students to accept, integrate and increase their initiative in cognition.

If students have unique cognitive problem, the teacher should try to solve this problem by relying on the self-created solving path. At the spare time, the teacher should assist students in considering the cognitive thought and discriminate the advantage and disadvantage of innovative thought to choose the optimal cognitive path by experience and balance.

(III) Discriminate the cognitive thought

Under the guidance of the origin of innovative cognition, students should discriminate the value of sports and accept the innovative teaching thinking consciously; mobilize the underlying cognitive enthusiasm and face the unique exercise process; accept the teacher's improvement suggestions modestly and insist on continuous exercise process; consult the teacher about the matters related to exercise modestly and promote the substitution and improvement of cognitive thinking. Only in this way, the new cognitive path can be created. 


\section{Disadvantages of existing method}

(I) No self research

The traditional cognitive thought is to change the usual cognitive psychological and make the unique subjects that accept teaching accept the preset subject contents happily. Under the traditional path, people only consider the unique dominant value of teacher and neglect the dominant position of students. The old cognitive thought hinders the mining of ability in physical education and suppresses the creative new thought.

The usual teaching lacks of initiative characteristics and suppresses the underlying enthusiasm of students. Most of the students in colleges accept the sports course for exam-oriented purpose. Under this situation, it is hard to mobilize students' cognitive enthusiasm and promote their all-around development.

(II) Barriers of old model

The teaching model under the traditional architecture is hard to accord with the physical and mental development in new times, in which the teacher is in the central position during teaching to pass on preset outline knowledge and impart the original knowledge of this subject, and the students accept such knowledge passively, without any doubt.

This path in the traditional architecture only passes on the preset principle of origin, sports-related exercise method and sports-based relevant skills. In this way, the teacher often neglects the self characteristics of students and fails to provide an opportunity of doubt. In addition, in case of any error in exercise, the teacher will rebuke the student. Therefore, the students have an emotion of fear for this subject, which distorts the preset teaching goal.

\section{Profile model under the innovative architecture}

(I) Effective new model

To create new teaching process, the thinking guidance under the advanced architecture should be accepted along with the creative practice at ordinary times, thus, the usual error and misunderstanding can be avoided. It is also required to follow the teaching principle in modern times and discriminate the real state characterized by students. The development trend can be discriminated only after careful research.

The filed segmented by the sports teaching is affected by the unique thought, such as modern information theory and control theory within the systematic architecture. The unique research subject of sports teaching should highlight the promotion of the change process preset by quality-oriented education and pay more attention to the unique cognitive value of this subject compared with the traditional teaching thought. The innovative model is divided into a new teaching thinking.

The teaching guidance preset by colleges should connect the sports basis at middle school; based on this, the new platform relied on by the talents cultivation is built and the higher creative quality is cultivated. If this platform is to be built, the usual basic thought and teaching mode of innovative education must be discriminated. After long-term progress, the innovative education builds the systematic architecture by relying on the common method. By reference to the existing advanced experiment and combined with the real state obtained by inspection, the optimal and proper teaching path is created.

(II) Improvement of quality level

The innovative thought relied on by sports cannot leave the high-quality teacher in colleges. The preset cultivation path covers multiple methods, such as teaching training at school and exercise and cultivation under the professional path. The common cognition and training should also be highlighted. The innovative teacher cultivation should build the best path and channel. The higher vocational colleges should develop the long-term cultivation plan based on the unique reality, optimize the original teaching mechanism and build the long-term professional mechanism, and improve the detailed professional configuration.

The innovative sports subject is closely related to the existing practice. The original foundation 
can be found by usual practice and the underlying potential problem can be found by innovation under such real situation to preset the solving path. The sports teaching should discriminate the practical integration mechanism and connect the fundamental mechanism in the outline architecture with detailed daily teaching to promote the improvement of cognitive level. It should also lead the students to use the fundamental mechanism into the usual exercise and continuously promote the self-improvement of students by practical inquiry.

In modern times, the intercommunication worldwide is frequent and the advanced cultivation model can be absorbed from the intercommunication and interaction. The selected teaching model can cultivated innovative and all-around talents. The subject position of students should be determined. The teacher should have high professional level and discriminate the established cognitive framework. At the same time, the spiritual cultivation within the category of innovation is integrated into the usual teaching. The present goal should have such characteristics as life-long education and the existing system should be deepened with the modern concept.

(III) Orderly acceptance and reference

The foreign subject experience covers multiple acceptable methods. The research involved by sports teaching has fast development rate and there are multi-level advanced experiences after long-term accumulation. The teacher should discriminate such guidance preset by sports teaching and promote the improvement of independent ability.

For example, example-based teaching, unique teaching process of advance organizer and self-study guidance under the auxiliary architecture well combine the preset subject architecture and make students improve their original cognitive level by independent understanding. The non-guiding new model and teaching procedure under the cooperative path mobilize the independent cognition. The preset methods are to make students accept the cognitive system by daily study in order to solve the usual real problems. The unique highlight model should be realized and the essence of model under the traditional architecture should be inherited.

It should be noted that the advanced experienced cannot be indiscriminately imitated and followed upon absorption. The physique state obtained by survey, unique cultural level of students and mental cognition of this subject should be followed and the segmented branches should be combined to gradually develop the proper new method.

\section{Segmented multiple methods}

The selected teaching method should have effective implementation path. The preset model utilization will show multi-level effects and the associated effects are different. For example, in analyzing the unique essentials of hurdle race, the deviation should be corrected properly. The students can carry out practice repeatedly to explore the key points of hurdle. The teacher can gradually elongate the starting point to make students learn unique forward lean in the continuous hurdle. In this way, the teaching effect can be manifested. Specially, the new method under the innovative horizon can be divided into the following levels:

(I) Highlight the reconciliation skills

The physical exercise process should reconcile each part and find the proper movement skills. Under the given objective situation, the reconciliation should be conducted properly to have preset exercise effects. In lesson preparation, the teacher should accumulate sufficient theoretical basis, orderly grasp the clear textbook clue and use the selected movement skills to improve the original normative and accurate movement. The students should properly reconcile each part of their body to avoid any unique accident.

(II) Promote the intercommunication and cooperation

The usual sports teaching is characterized by intercommunication. The real effects manifested by sports teaching involve multi-level elements. If a happy atmosphere can be created, students will be willing to accept new cognition and continuously find and actively solve the underlying movement problems. In the classroom, to relieve the pressure in exercise, some small games can be played to make students relaxed. The teacher should discriminate the unique psychological problem of students and really care students to make them understand the unique interest of sports subject. 
(III) Identify the feedback information

Under the teaching path of internal and external reconciliation, the external state characterized by students should be considered and the internal mental changes should also be highlighted. For example, the external changes characterized by students cover the face change upon exercise, unique change of sweat secretion, change of movement quality and movement speed. The above-mentioned changes are closely related to the underlying mentality of students.

The change of psychological activity, unique change of biology and change within the category of bioelectricity can be discriminated from the multiple feedback information. The careful inspection of after-class feedback information can help teacher discriminate the existing teaching problems and create the optimal new process.

(IV) Consider multiple emotions

The non-intelligence multiple elements will affect the teaching effects under the overall situation and the non-intelligence causes cover deep-level psychological causes. In the sports teaching, students' unique interest in this subject, cognitive mentality and inherent personality characteristics are covered in this category. The deep-level emotional elements can be converted into the original motivation of cognition.

The non-intelligence emotional elements can last for a long time and the motivation of internal characteristics is great. Therefore, it is necessary to deeply study the cause involved by emotion and carefully to stimulate this motivation. For example, play interesting video and interested associated short films for students by virtue of multimedia. This can broaden the existing visual category and enrich the deeper emotional interaction. The new model under the guidance of emotion has clear humanistic characteristics.

\section{Conclusion}

The innovative education is inclusive in the preset framework of quality education, which highlights the establishment of creative unique thinking and unique operation skills. The usual teaching should reserve the unique space for independent recognition. The teacher should conduct intercommunication and exchange to continuously accumulate the associated experience, and also create a happy and relaxed teaching atmosphere to eliminate the underlying fear and improve the exercise enthusiasm.

\section{References:}

[1] Liu Hong. Discussion on Theory and Practice of Sports Teaching Mode under Innovative Education Concept[J]. Technology Wind, 2014(11).

[2] Huo Jun, Su Peng. Research on Application of Sports Teaching Mode under Innovative Education Concept[J]. Sports Science Research, 2014(02).

[3] Peng Xiaowei, Yang Guoqing. Analysis and Recognition on Category of Contemporary Sports Teaching Method[J]. Journal of Shenyang Sport University, 2010(04).

[4] Nie Zhimin. Research on Characteristics of Traditional Sports Teaching Mode and Modern Sports Teaching Method [J]. Bulletin of Sport Science \& Technology, 2013(12).

[5] Lin Song. Discussion on Modern Sports Teaching Reform_-Innovative Sports[J]. Science \& Technology Information (Academic Research), 2006(07).

[6] Yang Yong. Application of Innovative Education Theory in Modern Sports Teaching[J]. Journal of China Three Gorges University (Humanities and Social Sciences), 2010(S2).

[7] Zhong Weizhi. Discussion and Research on Sports Teaching Mode and Innovative Education in Colleges[J]. Science Education Article Collects (Late of This Month), 2013(05).

[8] Cai Xiaolong. Discussion on Innovative Education in Modern Sports Teaching[J]. The Guide of Science \& Education (Middle of This Month), 2012(03).

[9] Wang Yangchun. Discussion and Research on Sports Teaching Mode and Innovative Education in Colleges[J]. Journal of Nanjing Sport Institute (Natural Science), 2008(04).

[10] Yuan Xingzhao. Innovative Education Concept Penetrated in Modern Sports Teaching[J]. Trade Unions' Tribune (Journal of Shandong Institute of Trade Unions' Administration Cadres), 2007(05). 